\title{
Advocacy for the Counseling Profession: Results of a National Survey
}

\author{
Jane E. Myers and Thomas J. Sweeney
}

Seventy-one leaders in state, regional, and national professional and credentialing associations in counseling responded to a survey concerning professional advocacy efforts, resources, obstacles, and needs. The results indicate a variety of ongoing advocacy initiatives, specific needs for resources and interprofessional collaboration, and agreement on the importance of advocacy for the future of the profession.

\section{A}

dvocacy, the process or act of arguing or pleading for a cause (Lee, 1997), includes social activism as well as the promotion of a profession. The counseling profession originated from concerns for clients (Brooks \& Weikel, 1996), thus advocacy on behalf of clients has traditionally been perceived as an integral part of the counselor's role (Lee \& Walz, 1998). Advocacy for the counseling profession emerged as a phenomenon of the late 20th century, as a direct consequence of the evolution of counseling as a separate and distinct mental health profession (Sweeney, 1995). Client needs and strategies for advocacy on behalf of clients have received considerable attention in the professional literature (e.g., Lee, 1997; Lee \& Walz, 1998; Smaby \& Daugherty, 1995; Torkelson-Lynch \& Gussel, 1996; White, Thomas, \& Nary, 1997); however, there is a virtual dearth of information relative to advocacy for the profession (Eriksen, 1997).

McClure and Russo (1996) suggested that professional advocacy involves siphoning resources away from client concerns by focusing them on areas of intraprofessional conflict, hence advocacy for the profession rather than for clients seems almost selfish or self-serving. This perspective places advocacy for clients and advocacy for the profession in direct conflict, rather than viewing them as complementary activities that are each necessary for specific purposes. The need for advocacy for the profession has been examined only sporadically (see Eriksen,1997) and may be succinctly summarized in the words of participants in a recent national conference on counselor advocacy: " $[\mathrm{I}] \mathrm{n}$ the absence of advocacy for the profession, the right to be a counselor serving any particular population would be very severely limited" (Chi Sigma Iota, 1998, Advocacy section, para. 1). If trained, credentialed professional counselors are to have the opportunity to access jobs commensurate with their preparation, concerted attention to advocacy for the profession is needed (Myers, 1995; Remley, 1995; Sweeney, 1995). Such attention must be based in the knowledge that advocacy is necessarily two pronged (i.e., advocacy for clients and advocacy for the profession) and that advocacy for the profession has the potential to place counselors in positions where they can advocate effectively for the causes of their clients.

The available literature fails to provide a sufficient knowledge base concerning existing advocacy efforts and needs that would enable effective planning for professional advocacy (Goetz \& Barstow, 1998; Nejedlo, Hansen, \& Myers, 1994). Furthermore, the lack of a comprehensive, coordinated national plan for counselor professionalization results in existing counselor advocacy efforts being fragmented, sporadic, and inconsistent (Bloom, 1996; Sweeney, 1995). The development of a national plan requires identification of both past and current advocacy efforts.

This article reports the results of a survey of leaders of counseling associations to determine their perceptions of activities and needs involved in advocacy for the profession. The purpose of the survey was to develop data on which to base future advocacy plans and that would serve as a baseline against which the success of future advocacy efforts could be gauged. The primary research questions addressed in the study were as follows:

1. What advocacy efforts are being and have been undertaken on behalf of credentialed professional counselors?

2. What are the advocacy needs of credentialed professional counselors?

3. What are the primary impediments to effective advocacy at the present time?

4. What are the primary methods that offer success in advocacy for credentialed professional counselors?

Jane E. Myers, Department of Counseling and Educational Development, The University of North Carolina at Greensboro; Thomas J. Sweeney, Counselor Education, Ohio University. The authors thank Naomi Mandsager for her assistance in collecting data for this survey. Correspondence conceming this article should be addressed to Jane E. Myers, Department of Counseling and Educational Development, 222 Curry Building, The University of North Carolina at Greensboro, Greensboro, NC 27402 (e-mail: jemyers@uncg.edu). 


\section{METHOD}

The first requirement for the present study was the development of a survey instrument, which is described below. Several counseling associations were contacted and funding was requested to support the study. Chi Sigma Iota, International, and the Public Policy and Legislation Committee of the American Counseling Association (ACA) agreed to provide funding for the study. In an attempt to obtain data concerning the advocacy activities of professional associations in counseling, we identified current leaders of professional counseling associations as the sample population for the study.

\section{Survey Instrument}

The survey for the study was developed based on an analysis of the literature relative to professional advocacy. Eight categories of questions were included: (a) demographic information about the respondent, (b) structure of advocacy efforts of the organization that the respondent represented, (c) nature and success of advocacy efforts by the organization, (d) the respondent's perception of current advocacy needs for the profession, (e) resources needed by the organization for advocacy efforts, $(\mathrm{f})$ existence of interprofessional alliances for advocacy and perceptions of the need for such alliances, (g) obstacles to effective advocacy, and (h) perceptions of the importance of advocacy for the future of the counseling profession.

An initial draft of the survey was reviewed by several leaders in the field, including the president of Chi Sigma Iota, International; the cochairs of the Public Policy and Legislation Committee of the ACA; and ACA public policy staff members. Feedback from these individuals was used to develop the final version of the survey instrument.

\section{Participants and Procedure}

ACA provided a set of 180 mailing labels for persons in the following positions: members of the ACA governing council, state branch presidents, division presidents; ACA past presidents; executive directors and board chairs of the Council for Accreditation of Counseling and Related Educational Programs (CACREP), the Council on Rehabilitation Education (CORE), the National Board for Certified Counselors (NBCC), and the Commission on Rehabilitation Counselor Certification (CRCC); chairs and past chairs of the ACA professionalization and public policy and legislation committee; and chairs of the ACA division and state branch public policy and legislation committee. A cover letter was included to explain the purpose and importance of the survey, and a self-addressed, stamped envelope was included to encourage responses.

\section{RESULTS}

A total of 71 completed surveys were received, with a response rate of $39 \%$. Funding did not permit a follow-up mailing or telephone calls to nonrespondents. The results, based on the 71 surveys, are presented in the following sections for each of the eight parts of the questionnaire.

\section{Demographic Description of Respondents}

Table 1 provides a summary of selected demographic descriptors for the 71 respondents. Slightly more than one third of the respondents $(35 \%)$ were professional counselors, and 1 in 5 (21\%) were counselor educators. Almost half $(45 \%)$ had a master's degree, and just over half $(51 \%)$ had a doctorate. The major field of study for most respondents was counseling (59\%), and for one fourth (24\%), the major field of study was psychology. However, most respondents' professional identity was not in psychology, as reflected in the fact that only $3 \%$ maintained a license as a psychologist. Forty-four percent were licensed professional counselors, and $31 \%$ were certified by the NBCC (i.e., $31 \%$ were national certified counselors). More than two thirds of the respondents $(69 \%)$ had been in the field for 16 or more years, and more than one third ( $41 \%$ ) had been counselors for more than 20 years. Only $10 \%$ had been in the field less than 5 years. The average number of years in the field was 21 .

\section{Structure of the Organization's Advocacy Efforts}

In the second part of the survey, we asked questions concerning the structure of the organization's advocacy efforts. The "organization" in this case referred to the entity that the individual represented as a professional leader (e.g., ACA governing council, state branch, ACA division). Thirty-seven of the respondents $(52 \%)$ indicated that their organization had a statement that required involvement in advocacy

\section{TABLE 1}

\section{Demographic Description of Respondents}

\begin{tabular}{|c|c|c|}
\hline Demographic Variable & $n$ & $\%$ Total \\
\hline \multicolumn{3}{|l|}{ Employment position } \\
\hline Counselor & 25 & 35 \\
\hline Counselor educator & 15 & 21 \\
\hline Other & 31 & 43 \\
\hline \multicolumn{3}{|l|}{ Years of experience as a professional } \\
\hline \multicolumn{3}{|l|}{ counselor } \\
\hline Less than 5 & 7 & 10 \\
\hline $6-10$ & 8 & 11 \\
\hline $11-15$ & 7 & 10 \\
\hline $16-20$ & 20 & 28 \\
\hline $21-30$ & 24 & 34 \\
\hline $30+$ & 5 & 7 \\
\hline \multicolumn{3}{|l|}{ Highest degree } \\
\hline Master's & 32 & 45 \\
\hline Doctorate & 36 & 51 \\
\hline Other & 3 & 4 \\
\hline \multicolumn{3}{|l|}{ Major field of study } \\
\hline Counseling & 42 & 59 \\
\hline Psychology & 17 & 24 \\
\hline Other & 12 & 17 \\
\hline \multicolumn{3}{|l|}{ Credentials } \\
\hline Licensed professional counselor & 31 & 44 \\
\hline National certified counselor & 22 & 31 \\
\hline Licensed psychologist & 2 & 3 \\
\hline Marriage and family therapist & 2 & 3 \\
\hline Other & 17 & 24 \\
\hline
\end{tabular}


activities for professional counselors, 35\% indicated that their organization did not have such a statement, $11 \%$ did not know if such a statement existed or not, and $2 \%$ did not respond. Among the 37 respondents who reported having such a statement, $22(31 \%)$ indicated that it was part of the mission statement and $28(39 \%)$ noted that it was part of the organization's strategic plan. Fifteen organizations included a statement on counselor advocacy in their bylaws. Fortysix organizations $(65 \%)$ had committees that included counselor advocacy as part of their charge. One half of the organizations $(51 \%)$ paid a fee for advocacy services, with $31 \%$ sponsoring a paid lobbyist and $24 \%$ paying a staff person to perform this function. In response to an open-ended request for comments, two state division presidents noted that, as nonprofit organizations, they were restricted in the amount of funds that could be paid for legislative lobbying on behalf of their members.

\section{Nature and Success of the Organization's Advocacy Efforts}

The next set of questions concerned the nature and the success of advocacy efforts by the organization. Respondents were asked to check the type of professionals who were the focus of their advocacy efforts; they could check more than one type from a list provided. Forty-eight $(67 \%)$ indicated that the focus of advocacy was licensed counselors, 35\% indicated that the focus was certified counselors, and $32 \%$ indicated that counseling specialties were the focus. Although most did not indicate which specialties were included, $10 \%$ noted that school counselors were the focus, $3 \%$ rehabilitation counselors, and $1 \%$ mental health counselors.

Respondents noted the overall success of their advocacy efforts on a 3-point scale. Six percent thought that they had not been successful, $51 \%$ that they had been moderately successful, and $30 \%$ that they had been highly successful. The various types of advocacy activities implemented and the relative success of each are shown in Table 2 . The most frequent types of activities, in descending order, were committees/volunteers (68\%), literature and information regarding advocacy (63\%), coalitions with other professional groups (59\%), and government relations liaisons (55\%). Paid con- sultants (24\%) and paid staff (31\%) were the least frequently used options. The highest levels of success were reported for the most frequently used types of advocacy activities.

The major groups formed coalitions that were social workers, psychologists, marriage and family therapists, nurse practitioners, psychiatrists, and mental health center staff. A few respondents indicated the formation of coalitions within the counseling profession, including the NBCC, national divisions of ACA, and state counseling associations.

Several respondents provided open-ended comments in response to the questions in this section of the survey. One person noted the need for increased membership involvement, and another indicated that Web links were being used for advocacy to promote the profession. Another noted that progress was often slowed because executive councils tried to determine the desired course of action for committees rather than empowering them to develop their own strategic goals.

\section{Perceptions of Current Advocacy Needs}

A list of seven possible needs was provided, and participants were asked to check which ones they considered to be current advocacy needs for the profession. The most frequently checked current advocacy need was to "improve the public and professional image of counselors" (87\%), followed by "publicizing counseling and services counselors provide" (75\%). "Pursuing legislative action on behalf of jobs for professional counselors" (69\%) and "assuring counselors have equal access to employment with other professionals" (69\%) were checked an equal number of times. "Assuring parity in pay for counselors with other mental health professionals" was checked by $61 \%$ of respondents, and "develop common definition/identity for professional counselors" was checked by $59 \%$. The least frequent option, which was checked far less often than the other choices, was "hiring paid staff/ consultants to advocate for professional counselors" (42\%).

Open-ended comments concerning perceptions of current advocacy needs were provided by 16 respondents (23\%). Most noted that, although all of the statements could be considered to be current advocacy needs, only a couple should receive a concerted emphasis at one point in time to ensure

\section{TABLE 2}

\section{Types and Success of Advocacy Activities Implemented}

\begin{tabular}{|c|c|c|c|c|c|c|c|c|}
\hline \multirow[b]{3}{*}{ Advocacy Activity } & \multirow{2}{*}{\multicolumn{2}{|c|}{$\begin{array}{l}\text { Implemented } \\
\text { Activity (If Yes) }\end{array}$}} & \multicolumn{6}{|c|}{ Success of Activity } \\
\hline & & & \multicolumn{2}{|c|}{ High } & \multicolumn{2}{|c|}{ Moderate } & \multicolumn{2}{|c|}{ Low } \\
\hline & $n$ & $\%$ & $n$ & $\%$ & $n$ & $\%$ & $n$ & $\%$ \\
\hline Committees/volunteers & 48 & 68 & 22 & 31 & 24 & 34 & 2 & 3 \\
\hline Advocacy literature/information & 45 & 63 & 13 & 18 & 25 & 35 & 7 & 10 \\
\hline Coalitions with professional groups & 42 & 59 & 14 & 20 & 22 & 31 & 5 & 7 \\
\hline Government relations liaisons & 39 & 55 & 15 & 21 & 20 & 28 & 2 & 3 \\
\hline Media opportunities (e.g., radio, television) & 34 & 48 & 7 & 10 & 13 & 18 & 13 & 18 \\
\hline Advocacy training packet & 33 & 47 & 10 & 14 & 13 & 18 & 9 & 13 \\
\hline Paid staff & 22 & 31 & 10 & 14 & 5 & 7 & 5 & 7 \\
\hline Paid consultants & 17 & 24 & 5 & 7 & 7 & 10 & 3 & 4 \\
\hline Other & 7 & 10 & 6 & 9 & 2 & 3 & - & - \\
\hline
\end{tabular}


successful outcomes. Respondents noted the need to direct advocacy efforts toward managed care companies $(n=3)$ and to develop a unified profession rather than one fragmented by specialties $(n=5)$.

\section{Available Resources for Advocacy}

In this section of the survey, respondents were asked to check which of a list of resources were available to them for advocacy purposes and which resources were needed. The responses to these questions are summarized in Table 3 . Committees and volunteers were by far the most frequent resource available (73\%), followed by coalitions (59\%) and government relations staff (58\%). Paid staff ( $28 \%)$, funding $(27 \%)$, and consultants (20\%) were the least frequently available. In contrast, funding was the resource cited as most needed ( $52 \%)$, with paid consultants $(25 \%)$, government relations staff $(31 \%)$, and literature about advocacy (32\%) being the least needed.

\section{Existence of and Need for Interprofessional Alliances}

Almost three fourths of the respondents $(74 \%)$ indicated that they had participated in coalitions with other professional groups in legislation or service areas related to professional counseling. The most frequent coalitions were with social workers, and the most common comment was that coalitions were formed for the purpose of supporting legislation for client issues.

\section{Obstacles to Advocacy}

Respondents were asked to check items in a list that they considered to be among the primary obstacles to advocacy efforts. In descending order, the following obstacles were noted: inadequate resources (58\%), not enough money (51\%), opposition by other providers (51\%), lack of collaboration $(47 \%)$, resistance of public policy makers $(42 \%)$, lack of training in advocacy $(41 \%)$, not enough time to deal with

\section{TABLE 3}

\section{Available and Needed Resources for Counselor Advocacy}

\begin{tabular}{|c|c|c|c|c|}
\hline \multirow[b]{2}{*}{ Resources } & \multicolumn{2}{|c|}{$\begin{array}{c}\text { Have } \\
\text { Available? }\end{array}$} & \multicolumn{2}{|c|}{$\begin{array}{c}\text { Resources } \\
\text { Needed? }\end{array}$} \\
\hline & $n$ & $\%$ & $n$ & $\%$ \\
\hline $\begin{array}{l}\text { Committees/volunteers } \\
\text { Coalitions with professional }\end{array}$ & 52 & 73 & 26 & 37 \\
\hline $\begin{array}{l}\text { groups } \\
\text { Government relations }\end{array}$ & 42 & 59 & 26 & 37 \\
\hline liaisons & 41 & 58 & 22 & 31 \\
\hline $\begin{array}{l}\text { Advocacy literature/ } \\
\text { information }\end{array}$ & 36 & 51 & 32 & 32 \\
\hline $\begin{array}{l}\text { Media opportunities (e.g., } \\
\text { radio, television, Internet) }\end{array}$ & 28 & 39 & 31 & 44 \\
\hline Advocacy training packet & 23 & 32 & 31 & 44 \\
\hline Paid staff & 20 & 28 & 27 & 38 \\
\hline Funding & 19 & 27 & 37 & 52 \\
\hline Paid consultants & 14 & 20 & 18 & 25 \\
\hline
\end{tabular}

advocacy (39\%), lack of advocacy leadership (39\%), lack of awareness of advocacy issues (35\%), not a priority (28\%), little interest in advocacy (27\%), and not having a training packet in advocacy $(18 \%)$.

Although respondents were given space and asked to provide open-ended comments in response to each part of the survey, in most cases they did not do so. In contrast, almost one third of the respondents provided narrative responses or comments on the question of obstacles. The concerns expressed ranged from a belief that counselors are apathetic to concerns that the many demands of the profession leave little time for advocacy activities. Several respondents noted that politics is an issue, and others expressed concern that the need to survive in a competitive marketplace takes so much energy that none is left to address the broader issues. Some respondents considered that "no one is willing to make the commitment," while others reflected on the fact that counselors are reluctant to "toot our own horn." Two respondents identified the lack of unity in the profession as a major obstacle.

\section{Importance of Counselor Advocacy}

The final question in the survey asked respondents to circle a number from 1 to 3 to represent their perception of the importance of counselor advocacy to the future of the counseling profession, with 1 being most important and 3 being not at all important. Four percent circled 3, 14\% circled 2, $79 \%$ circled 1 , and $3 \%$ did not respond.

\section{DISCUSSION}

The respondents to this survey were identified based on their leadership positions in the counseling field. Thus, it was not surprising that the average number of years in the profession was high (i.e., 21). It is encouraging that most respondents had degrees and credentials in counseling and identified themselves as professional counselors. Based on their involvement in the field, the perceptions of these leaders relative to advocacy likely reflect the sentiments of many professional leaders at this time. Although it is probable that those who responded were more interested and involved in advocacy than the leaders who did not respond, the large number of nonrespondents $(61 \%)$ make conclusions about the meaning of the results tentative, possibly reflecting trends rather than being definitive.

The importance of advocacy is reflected in the fact that slightly more than half of the professional organizations represented by the leaders had statements requiring advocacy activities. On the other hand, the lack of such statements for the remaining entities suggests a need for dialogue among the members of the boards of counseling organizations, particularly given the importance accorded to this function in other survey responses. Most notable here is the fact that $96 \%$ of the respondents considered advocacy to be a moderately or (primarily) highly needed professional activity. The lack of counseling organizations' commitment to advocacy through 
written statements and policies is clearly an area that needs to be addressed if advocacy efforts are to be increased.

The fact that advocacy efforts have been focused primarily on issues associated with the laws, regulations, and concerns of licensed counselors is not surprising. The passage of licensure laws in a state does not negate the need for continued advocacy in this area, because changes in legislatures and reauthorizations of legislation place the specifics of licensure laws in continual jeopardy. In addition, third-party payers, school boards, and other employers of counselors are often unaware of counselors' educational background, scope of practice, or credentialing requirements. It was notable that almost one third of the respondents included advocacy for specialties in their organization's efforts. This result may reflect the organization-specific nature of the participants (e.g., representatives of the American School Counselors Association or the American Mental Health Counselors Association to the ACA governing council) whose primary professional interests are associated with their specialty within counseling and not with the profession of counseling as a discipline of the whole. Such fragmentation, as noted by several respondents in open-ended comments, may act to undermine overall advocacy efforts for the counseling profession as a whole.

It was noteworthy that participants considered the advocacy efforts in which they had been engaged to be moderately to highly successful (81\%). The involvement of volunteers in advocacy activities seems to be the most effective and most frequently implemented strategy. The positive side of this fact is that the success of advocacy efforts may reflect the energy, commitment, and expertise of the volunteers. At the same time, the lack of success of such efforts may reflect a lack of time, resources, or skill at the volunteer level. Unfortunately, it is impossible to determine the specific reasons for responses on this topic because the survey simply did not provide a mechanism to address this issue.

Participants' perceptions of current advocacy needs clearly point to the public image of counseling and counselors as the area of greatest need, surpassing or perhaps serving as a precursor to advocacy for greater consideration of professional counselors for available jobs. It is clear that participants in this survey believe that the public lacks awareness of who professional counselors are as well as the services we provide. Perhaps efforts to enhance the public image of the counseling profession, if successful, would result in greater access to jobs as a direct by-product of greater public awareness of counseling's identity.

The fact that paid staff and consultants were not viewed as needed (by more than half of the respondents) to advocate for counselors was interesting. Traditionally, our profession has lacked the resources to hire staff and consultants for this function. Thus, we may be unaware of the potential benefits to be gained from doing so. A review of the legislative successes of ACA that have occurred since the time that public policy staff have been employed could be useful. If reports prepared by these staff members are any indication of what might be expected (Goetz \& Barstow, 1998), then per- haps, as a profession, we need to reconsider how best to reallocate resources to spend more in this vital area.

The inverse relationship indicated in the survey responses between available resources for advocacy and perceptions of needed resources was of interest (see Table 3 ). The seemingly contradictory statement being made by respondents almost seems to be "What we don't have is what we want; at the same time, what we do have is sufficient." Clearly, participants believe that more funding is needed to support advocacy efforts, while paid staff and consultants, again, were neither used nor desired by four fifths of those responding.

Both media opportunities and training packets were identified as needs; however, the lack of a training packet for advocacy was ranked lowest in the list of obstacles to advocacy. It seems that advocacy training materials may, in fact, be available in some organizations and that participants view these materials as an important part of their advocacy efforts. The resources that seem to be most lacking include money and time, which, combined with opposition from other mental health service providers and lack of effective coalitions with professional groups in the field of mental health, inhibit the success of advocacy efforts.

\section{CONCLUSION}

The results of a national survey of ACA leaders concerning advocacy for the counseling profession reveal a number of effective advocacy activities currently being implemented. Further research is needed to verify the current findings and to develop a database relative to counselor advocacy. Studies of the advocacy activities of professional counselors as well as counseling leaders are needed. Both survey research concerning advocacy content in counselor preparation curricula and strategies for teaching advocacy skills would be useful. The characteristics of effective advocates have not been identified, nor have strategies for recruiting and training potential advocates been studied. Best-practice research would be useful to identify the components of successful advocacy programs and provide models for such activities. Strategies for effective advocacy for employment of professional counselors, including recognition of counselor credentials and licensure as being equivalent to that of other mental health providers, are needed to inform the advocacy efforts of professional counselors and counseling associations. Similarly, successful strategies for creating and enhancing interprofessional alliances are needed to serve as models across states in counselor advocacy efforts, as are strategies for overcoming opposition by other mental health providers to counselor employment and reimbursement for services. Additional research and/or program initiatives are also needed to identify successful strategies for improving public perceptions of professional counseling. Integral to such initiatives is the ongoing need to support a unified definition of the profession.

Although advocacy for professional counselors is viewed as an important, even critical, need by leaders in our field, the lack of a coordinated effort among counseling organizations 
seems a more significant barrier to success than the lack of any of the available resources for this function. Counseling organizations are encouraged to initiate dialogues concerning the importance of professional advocacy, to develop policy statements concerning advocacy, and to develop coalitions in support of advocacy for the counseling profession. Counselor educators have a vital role to play in advocacy efforts by emphasizing the importance of advocacy for the counseling profession and of preparing professional counselors with the necessary knowledge and skills to be effective advocates for their profession as well as for the clients they serve.

\section{REFERENCES}

Bloom, J. W. (1996). Credentialing professional counselors for the 21st century. In J. W. Bloom (Ed.), Credentialing professional counselors for the 21st century (pp. 1-2). Greensboro, NC: ERIC/Cass Publications.

Brooks, D. K., \& Weikel, W. J. (1996). Mental health counseling: The first twenty years. In W. J. Weikel \& A. J. Palmo (Eds.), Foundations of mental health counseling (pp. 5-29). Springfield, IL: Thomas.

Chi Sigma Iota. (1998, May). Chi Sigma Iota counselor advocacy leadership conference proceedings (part 1). Retrieved September 23, 2004, from http://csi.affiniscape, com/displaycommon.cfm? an= $1 \&$ subarticlenbr $=70$

Eriksen, K. (1997). Making an impact: A handbook on counselor advo. cacy. Washington, DC: Taylor \& Francis/Accelerated Development.
Goetz, B., \& Barstow, S. (1998). An insider's/outsider's view of the profession today. Unpublished report. (Available from Jane E. Meyers, Departmant of Counseling and Educational Development, 222 Curry Building, University of North Carolina at Greensboro, Greensboro, NC 27402)

Lee, C. (1997). Multicultural issues in counseling: New approaches to diversity. Alexandria, VA: American Counseling Association.

Lee, C., \& Walz, G. (1998). Social action: A mandate for counselors. Alexandria, VA: American Counseling Association.

McClure, B. A., \& Russo, T. R. (1996). The politics of counseling: Looking back and forward. Counseling and Values, 40, 162-174.

Myers, J. E. (1995). Specialties in counseling: Rich heritage or force for fragmentation? Journal of Counseling \& Development, 74, 115-116.

Nejedlo, B., Hansen, S., \& Myers, J. E. (1994). A strategic plan for AACDs future: The precursors of ACA. Joumal of Counseling \& Development, 72, 276-281.

Remley, T. P. (1995). A proposed alternative to licensing of specialties in counseling. Journal of Counseling \& Development, 74, 126-129.

Smaby, M. H., \& Daugherty, R. (1995). The school counselor as leader of efforts to have schools free of drugs and violence. Education, 115, 612-621.

Sweeney, T. J. (1995). Accreditation, credentialing, professionalization: The role of specialties. Journal of Counseling \& Development, 74, 117-125.

Torkelson-Lynch, R., \& Gussel, R. (1996). Disclosure and self-advocacy regarding disability-related needs: Strategies to maximize integration in postsecondary education. Joumal of Counseling \& Development, 74, 352-356.

White, G., Thomas, R., \& Nary, D. (1997). An empirical analysis of the effects of a self-administered advocacy letter training program. Rehabilitation Counseling Bulletin, 41, 74-87. 